Collection: COST Action FP0905

"Biosafety of forest transgenic trees and EU policy directives"

Guest Editors: Cristina Vettori, Matthias Fladung

\section{Categorization of field trials with GM plants in the Netherlands: applicable to field trials with GM forest trees?}

\section{Debora CM Glandorf}

In the Netherlands, criteria have been set for field trials with genetically modified (GM) plants. These criteria are based on the step-by-step principle as described in European Directive 2001/18/EC. Three categories of field trials are defined. The first category concerns small-scale field trials with GM plants that are not well characterized on the molecular and phenotypic level. Confinement measures are applied in order to limit potential adverse effects to the field location. The second category consists of small-scale field experiments with GM plants that are better characterized. Confinement measures are no longer necessary since sufficient information is available to assess potential adverse effects on human health and the environment for these trials. The third category consists of large-scale field trials with fully characterized GM plants and without the need of confinement measures. For each category, a new permit is required. This system has been used for several crops, including apple and poplar trees and may also be applicable for trials with GM forest trees.

Keywords: Field Trials, Genetically Modified, GM Crops, GM Trees, Environmental Risk Assessment

\section{Introduction}

Field trials are an essential step in the selection process of suitable plants that may be of commercial interest. For the development of a new plant variety several steps are necessary. After development and first selection, promising plant lines are tested under field conditions to study their phenotype.

This is followed by further selection and commercialization of a small subset of plants with only the desired phenotype. For the selection of GM plants the same principle applies. However, whereas no safety assess-

$\square$ GMO Office, National Institute of Public Health and the Environment, P.O. Box 1, 3720 BA Bilthoven (the Netherlands)

@ Debora Cornelia Maria Glandorf (boet.glandorf@rivm.nt)

Received: Apr 10, 2014 - Accepted: Jul 25, 2014

Citation: Glandorf DCM, 2015. Categorization of field trials with GM plants in the Netherlands: applicable to field trials with GM forest trees? iForest 8: 222-225 [online 2014-08-31] URL: http://www.sisef.it/ iforest/contents/?id=ifor1311-008

Communicated by: Elena Paoletti ment and regulation applies to field trials with non-GM plants, trials with genetically modified plants are subject to regulation under Directive 2001/18/EC and an environmental risk assessment according to the principles of this Directive is mandatory. According to this Directive field trials should follow the step-by-step principle, which describes that: "the containment of GMOs is reduced and the scale of release increased gradually, step by step, but only if evaluation of the earlier steps in terms of protection of human health and the environment indicates that the next step can be taken".

In this paper, a system is described for the categorization of field trials that is based on the development of GM plant products and is in line with the step-by step principle. This system can be applied to all field trials, irrespective the purpose of the trial. This system is based on an advice of the Netherlands Commission of Genetic Modification (COGEM) where experience with this system has been gained in the Netherlands since 1999. This system may also be used for field trials with GM forest trees.

\section{Legislative framework}

Field trials with GM plants are regulated in the European Union (EU) under part B of Directive 2001/18/EC on the deliberate re- lease into the environment of genetically modified organism (EC 2001). In contrast to commercial release of GM plants, which is decided upon on a European level, the decision to grant field trials is taken at the national level. Each EU Member State has to implement Directive 2001/18/EC into its national legislation. The Directive grants the Member States some freedom in exercising and interpreting legal rights. This may lead to differences in procedures between EU Member States for obtaining a permit for field trials.

In the EU, a field trial application with GM plant must contain information on the GMO, its potential interaction with the environment, the environment the GMO will be introduced in (including locations where the trial may take place), a monitoring plan, an emergency plan and a risk assessment. Other EU Member States will be informed of the application for a field trial and comments of these Member States have to be taken into account in the final decision on the field trial.

In the Netherlands, once a permit is obtained for a field trial with GMOs, the permit holder has to indicate before the start of each growing season if he/she will make use of the permit and what locations will be used. A report, including the results of monitoring, has to be filed at the end of each year.

\section{Principles of environmental risk} assessment of GMOs

The objective of the environmental risk assessment (ERA) is to identify and evaluate potential adverse effects on human health and the environment. The ERA is conducted with a view to identify if there is a need for risk management and if so, the most appropriate methods used.

The ERA is comparative, i.e., any potential adverse effects of the GM plant are compared to that of the non-GM counterpart (nearisogenic, unmodified variety) and its use under corresponding situations. Furthermore, the ERA is case-by-case and should be conducted in a scientific and transparent matter. The steps in the ERA are illustrated in Fig. 1 .

In the first step the potential adverse effects of the specific GM plant (hazards) are identified, which will depend on the specific crop/ trait combination (case-by-case principle). The potential consequence of this adverse effect and the likelihood that this will occur is evaluated. This will determine the risk of the specific GM plant (risk $=$ hazard $\times$ likelihood). If a risk is identified, risk management strategies can be applied to decrease the risk, such as isolation distances of removal of inflorescence to prevent outcrossing. Finally, the overall risk will be determined, taking into account potential manage- 


\begin{tabular}{|c|c|c|c|}
\hline & \multicolumn{2}{|c|}{$\begin{array}{l}\text { Step 1: Identification of characteristics which may cause } \\
\text { adverse effects }\end{array}$} & \\
\hline \multicolumn{2}{|c|}{$\begin{array}{l}\text { Step 2: Evaluation of the potential consequences of each } \\
\text { adverse effect, if it occurs }\end{array}$} & \multicolumn{2}{|c|}{$\begin{array}{l}\text { Step 3: Evaluation of the likelihood of the occurrence of } \\
\text { each identified potential adverse effect }\end{array}$} \\
\hline & \multicolumn{2}{|c|}{$\begin{array}{l}\text { Step 4: Estimation of the risk posed by each identified } \\
\text { characteristic of the } G M O(s)\end{array}$} & \\
\hline & \multicolumn{2}{|c|}{$\begin{array}{l}\text { Step 5: Application of management strategies for risks } \\
\text { from the deliberate release or marketing of } \\
G M O(s)\end{array}$} & \\
\hline & \multicolumn{2}{|c|}{ Step 6: Determination of the overall risk of the $\mathrm{GMO}(\mathrm{s})$} & \\
\hline
\end{tabular}

Fig. 1 - The six steps of Environmental Risk Assessment, according to Directive 2001/18/ EC. ment strategies. In general, a field trial will only be approved if the overall risk is considered "low" or "negligible".

Directive 2001/18/EC states that the ERA of GM plants has to conclude on nine hazards. These hazards are:

1. potential persistence and invasiveness as a consequence of the GM trait;

2. selective advantage or disadvantage conferred to the GM plant;

3. gene transfer to the same or other sexual compatible plant species and any selective advantage and disadvantage conferred to these plants;

4. potential effects resulting from interaction between the GM plant and target species;

5 . potential effects resulting from interaction between the GM plant and non-target species;

6. potential effects from the GM plants on human health (e.g., persons working with GM plant or come into contact with the plants);

7. potential effects from the GM plants on animals and consequences for the feed/ food chain if the GM plants are used as animal feed health;

8. potential effects on biogeochemical processes;

9. potential effects of the specific cultivation, management and harvesting techniques of the GM plant if they are different from those used for non-GM plants.

\section{Categorization of field trials in the Netherlands}

According to Directive 2001/18/EC, the introduction into the environment of GM plants in field trials should be performed in a step-wise way. The underlying principle of this step-by-step approach is that confinement of GM plants can be gradually decreased and the scale of the introduction can subsequently be increased in a step-wise manner, under the condition that the conclusion of the ERA of the former steps allows the next step.

Based on this principle, COGEM proposed a system consisting of three categories of field trials for GM plants (COGEM 2005, 2008a). These categories are more or less based on the regular process of plant breeding in which field trials are an essential step in the selection process of suitable plants that may be of commercial interest. The idea is that during the selection process the level of characterization of the GM plants will increase and that more knowledge (both quantitative and qualitative) and experience will be gained in relation to the GM plants and its interactions with the environment. For GM plants this knowledge is obtained by a characterization of the GM plant at the molecular, phenotypic and ecological level. In addition, experience on environmental interactions is gained by obligatory monitoring on (un)expected effects of the plant on the

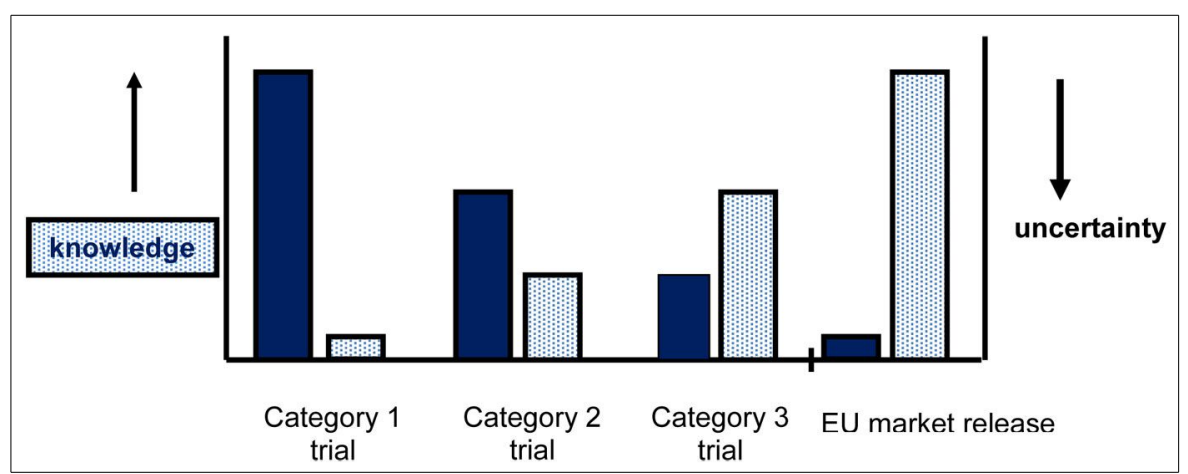

Fig. 2 - Step-by-step approach of field trials in the Netherlands (after COGEM 2005, 2008a). environment. Due to the increased knowledge of the plants and their environmental interactions, confinement measures may no longer be necessary and the scale of the field trial can subsequently be increased. This is illustrated in Fig. 2.

Following this approach, the first category of field trials can be used to test (many) uncharacterized plants as a first step in the field. There will be uncertainty with regard to environmental interactions related to the low level of characterization of the plants. Therefore, depending on the crop/trait combination, confinement measures are applied such as isolation distances or removal of inflorescence. The scale of the trial is limited to a maximum of five locations of one hectare per year. Based on data obtained in the first category field trial, or based on data from other field trials or from literature, one can apply for the second category of field trials. This second category is meant to further characterize a subset of earlier tested plants. Based on the outcome of the ERA, the use of confinement measures to prevent outcrossing are not considered necessary. However, due to the remaining uncertainty, the scale of the field trials is limited to a maximum of 10 hectares per year. Therefore there is still a form of confinement due to the level of the trial size in this category. The third and last category is meant for pre-commercial field trials for a single fully characterized event, for which is proven in earlier trials that adverse effects on human health and the environment are unlikely. There is no limitation to the scale of the field trial locations and measures for confinement with respect to outcrossing and the scale of the trial are not deemed necessary. For each category of field trial a new permit and a new ERA is obligatory.

For all field trials a monitoring plan is mandatory, since monitoring plays an important role in gathering data on environmental effects in the trials. Monitoring consists of general monitoring (phenotype, general agronomic features, any unexpected effect) and, depending on the crop/trait combination, specific monitoring.

Each category of field trials has its requirements on the level of characterization of the GM plant and its interaction with the environment. These requirements are meant to apply to all GM plants and are thus independent of the crop/trait combination (see below). On a case-by-case basis specific data requirements may be necessary for each category. In case the applicants want to scale up their experiments and want to apply for a next category of field trial, it can be indicated in the scientific advice of COGEM which specific requirements are considered necessary for the next category of field trial. In this manner, the applicant can gather the relevant data in advance. 


\section{Data requirements for categories of field trials}

The data requirements for each of the three categories of field trials, as described by $\mathrm{CO}$ GEM (2008a), are reported below.

\section{Category 1: small-scale field trials with confinement measures}

The size of the field trials is restricted to a maximum of five locations of one hectare each per year.

Requirement with respect to the characterization of the GM plant:

- For the introduced genes and regulatory elements: the genetic element(s) that could be inserted, the donor and the expected function(s) after expression of the genetic element(s) in the plant should be given.

COGEM (2008a) states in her advice that "results from earlier laboratory, greenhouse or field experiments with the same or comparable GM plants should be assessed on potential effects of the expression of the introduced genes". In other words, potential adverse effects as a consequence of expression of the newly introduced genes in the GM plant should be assessed. In order to do this, available experimental data obtained with the same of similar GM plants can be used. In addition, COGEM states that "the potential for adverse effects should be limited to the field location". This means that dispersal of the GM plant itself or by outcrossing should be prevented for this category of field trials, for example by removing inflorescence.

\section{Category 2: small-scale field trials without confinement measures}

There is no limitation to the number of locations, however per year the maximum size of all locations should not exceed 10 hectares.

Confinement measures to prevent outcrossing are no longer considered necessary.

Requirements with respect to the characterization of the GM plant:

- The same as for category 1

- A (plasmid) map indicating the genes used for genetic modification. From this map it should be apparent which combinations of genes, regulatory sequences and other elements for selection are used for modification.

- An assessment of the consequences of expression of these genes, based on results from earlier experiments (e.g., category 1) with the same or similar plants.

In the advice it is further stated that "there should be no reasons to assume that the GM plant itself or its offspring is harmful for human health and the environment" and "the introduced genetic material is not harmful for human health and the environment after outcrossing". In other words, based on knowledge of the introduced genetic mate- rial, its expression in the GM plant and outcome of earlier trials (category 1 or other trials in the EU), the risk assessment should not indicate any adverse environmental effects.

\section{Category 3: Large-scale field trials}

There are no limitations to the number of locations or the maximum size of locations.

Confinement measures (outcrossing, trial size) are not considered necessary.

Requirements with respect to the (molecular) characterization of the GM plant are the same as for an application for commercial release. As indicated for category 2 trials COGEM also states for category 3 trials that "there are no reasons to assume that the GM plant itself or its offspring is harmful for human health and the environment" and "the introduced genetic material is not harmful for human health and the environment after outcrossing."

\section{Examples of field trials}

\section{Category 1 trial}

An example of a category 1 field trial, in the Netherlands, is a trial with potatoes resistant to Phytophthora infestans, the cause of late blight. The application complied with the requirements for a category 1 trial. A distance of 3 meter was considered sufficient to prevent outcrossing, since the potential of outcrossing to other potato cultivars is low and will only occur over short distances. In the final permit, an obligation was included to monitor for volunteers for at least two years.

Another example is low lignin poplar for bioethanol production grown in a short rotation coppice. To prevent spreading of the poplar outside the field location, removal of inflorescence, wood suckers and falling branches was required (COGEM 2008b). Monitoring on wood suckers should take place for at least two years.

\section{Category 2 field trial}

An example is a trial with starch potatoes genetically modified to lower the amylose (starch) content. Earlier (category 1) trials with a the same and similar GM starch potatoes had been performed and results from monitoring (both qualitative and quantitative) indicated no adverse effects on human health and the environment. No confinement measures were deemed necessary, except for the limitation of the trial size to a maximum of 10 hectares.

A second example is a small-scale field trial with scab-resistant apple trees. The trees were modified with a resistance gene obtained from apple, which is already present in commercial apple varieties and in natural apple populations. The absence of vector backbone sequences was confirmed. The field plot was located at a distance of 150 meters from any other apple trees and 500 meters from commercial apple orchards. This distance was not considered enough to prevent outcrossing. However, based on the risk assessment no (additional) confinement measures were necessary (COGEM 2010).

\section{Category 3 field trial}

Following earlier field trials, an application was granted for large-scale trials with a single potato event with low amylose starch content. The GM potato was full characterized on the molecular level. Based on knowledge obtained from monitoring of earlier performed field trials it was concluded that potential adverse effects on human health and the environment were negligible.

There are no examples of category 3 trials with GM trees in the Netherlands.

\section{Discussion}

The categorization system for field trials in the Netherlands is applied since 2005 and was preceded by a similar system which consisted of five categories (COGEM 1999). The system as described in this paper is based on the plant breeding selection process but can be used for any GM field trial, such as trials for scientific research or trials for registration of new GM plant varieties. These latter field trials take at least two years and are mandatory to register a new plant or fruit tree variety on a national and European list. The advantage of the categorization of field trials is that applicants know in advance which data have to be submitted for an application. Moreover, they are able collect data that are necessary for an application for commercial cultivation of the GMO in the EU in a step-wise manner.

The system seems to work well in the Netherlands and has been applied for several GM crops, for example GM apple trees and GM poplar without problems. Obviously, the requirements for each category are rather general and specific data will be necessary for the risk assessment on a case-by-case basis. In the Netherlands, applicants are encouraged to discuss their draft application beforehand with the GMO Office before officially filing it. This gives applicants the opportunity to discuss and ask guidance on the specific case-by-case aspects.

In certain EU member states it is difficult to get regulatory permission for field trials, especially for GM trees. The system as described above may be a helpful tool to aid the approval process for GM trees, as was illustrated for small-scale (category 1 and 2) field trials with low-lignin poplar and flowering apple trees. These trials are relatively confined, either by the measures taken or because of the size and/or spatial separation. The challenge will be the ERA of unconfined large-scale trials with GM (forest) trees, 
as a pre-commercial stage. The ERA for these unconfined trials is different than that from confined trials. Obviously, sufficient information should be available from earlier trials with the same and similar GM trees and its interaction with the environment, for example from category 2 trials. As for any ERA, the ERA of these trials will depend on the specific tree/trait combination and potential effects will be compared with those of the non-GM tree. There is often already quite some knowledge on the biology of the non-GM tree species and is interaction with the receiving environment. This is especially true for intensively managed systems such as plantation forests (Häggman et al. 2013). Many of the introduced traits in GM trees are not new, as compared to those introduced in GM plants. Experience already exists with the ERA of those traits. The difference between GM trees and crops that are relevant for the ERA is - among others - their longevity and ability to disperse (Aguilera et al. 2013). These aspects are not new but may need more emphasis in the ERA of field trials with GM forest trees and may require some changes in data types and collection.

It is concluded that the described categorization of field trials in the Netherlands can also be applied for field trials with GM forest trees.

\section{Acknowledgements}

The author acknowledges the EU COST action FP0905 "Biosafety of transgenic trees and EU policy directives" and Frank van der Wilk (COGEM) and Jeanette Gómez Contreras (RIVM/VSP) for critically reading the manuscript. This work is presented at the final conference of the COST action FP0905 held in Rome on May 4 and 5, 2014.

\section{References}

Aguilera J, Nielsen K, Sweet J (2013). Risk assessment of GM trees in the EU: current regulatory framework and guidance. iForest 6 (3): 127131. - doi: 10.3832/ifor0101-006

COGEM (1999). Richtlijnen van de COGEM bij de beoordeling van veldproefaanvragen [Guidelines of COGEM for the assessment of field trial applications]. CGM/99-0518-41. [in Dutch] [online] URL: http//www.cogem.net

COGEM (2005). Advies indeling veldwerkzaamheden genetisch gemodificeerde planten [Advice on the categorization of field trials with genetically modified plants]. CGM/050929-03. [in Dutch] [online] URL: http://www.cogem.net

COGEM (2008a). Herziening advies indeling veldwerkzaamheden genetisch gemodificeerde planten [Reconsideration of the advice on the categorization of field trials with genetically modified plants]. CGM/081125-02. [in Dutch] [online] URL: http://www.cogem.net
COGEM (2008b). Advies categorie 1 veldproef met genetisch gemodificeerde populier [Advice on a category 1 field trial with genetically modified poplar]. CGM/ 081205-01. [in Dutch] [online] URL: http://www.cogem.net

COGEM (2010). Advies veldproef met genetisch gemodificeerde appelbomen [Advice on a field trial with genetically modified apple trees]. CGM/101214-01. [in Dutch] [online] URL: http://www.cogem.net

EC (2001). Directive 2001/18/EC of the European Parliament and of the Council of March 2001 on the deliberate release into the environment of genetically modified organisms and repealing Council Directive 90/220/EEC. Official Journal of the European Communities L106: 1-38. [online] URL: http://eur-lex.europa.eu

Häggman H, Raybould A, Borem A, Fox T, Handley L, Hertzberg M, Lu MZ, Macdonald P, Oguchi T, Pasquali G, Pearson L, Peter G, Quemada $\mathrm{H}$, Séguin A, Tattersall K, Ulian E, Walter C, McLean M (2013). Genetically engineered trees for plantation forests: key considerations for environmental risk assessment. Plant Biotechnology Journal 11 (7): 785-98. - doi: 10.11 11/pbi. 12100 